\title{
Nitrogênio e idade de corte na qualidade da biomassa de capim- elefante para fins agroenergéticos cultivado em Latossolo
}

\author{
Nitrogen and age on the quality of elephant grass for agroenergy \\ purpose grown in Oxisol
}

\author{
Rilner Alves Flores ${ }^{1 *}$; Segundo Urquiaga ${ }^{2}$; Bruno José Rodrigues Alves ${ }^{2}$; \\ Leonardo Santos Collier ${ }^{3}$; Juliano Brás Zanetti'; Renato de Mello Prado ${ }^{5}$
}

\section{Resumo}

\begin{abstract}
Atualmente um dos grandes desafios para a pesquisa de agroenergia é a produção de material energético alternativo derivado da biomassa vegetal. Aliado a isso, o manejo adequado do nitrogênio, torna-se fundamental para obter ganhos de produtividade e melhoria na qualidade da biomassa de capim-elefante. Desse modo, objetivou-se avaliar o efeito da adubação nitrogenada e da idade de corte do capimelefante (Pennisetum purpureum) na qualidade da biomassa da forrageira para fins agroenergéticos. O experimento foi realizado com o genótipo Paraíso, cultivado em um Latossolo Vermelho Amarelo distrófico no sul do Estado de Tocantins. O delineamento experimental foi de blocos casualizados com parcelas subdivididas, localizando-se nas parcelas as doses de nitrogênio $\left(0,50,100\right.$ e $\left.150 \mathrm{~kg} \mathrm{ha}^{-1}\right) \mathrm{e}$ nas subparcelas a idade de corte (120, 150 e 180 dias após o plantio), quatro repetições. Avaliaram-se as relações carbono:nitrogênio $(\mathrm{C}: \mathrm{N})$ e colmo:folha $(\mathrm{C}: \mathrm{F})$, teores de fibras em detergente neutro (FDN) e os teores de cinzas produzidas na biomassa seca. A aplicação de nitrogênio incrementou em $12 \%$ a relação C:N da planta. A maior idade de corte da forrageira incrementou-se em $9 \%$ a relação C:N da planta, entretanto, diminuiu em 12 e $14 \%$ os teores de cinzas produzidas no colmo e nas folhas, respectivamente. A produção de capim-elefante para fins agroenergéticos é viável com o sistema de manejo proposto, pois apresentou características qualitativas desejáveis, como alta relação $\mathrm{C}: \mathrm{N}$, acima de 40 e altos teores de fibras, acima de $50 \%$.

Palavras-chave: Pennisetum purpureum, adubação nitrogenada, bioenergia
\end{abstract}

\begin{abstract}
Nowadays one of the major challenge for research is the production of alternative agrifuels energy material derived from plant biomass. Allied to this, the proper management of nitrogen, becomes fundamental for productivity gains and improvement in quality of elephant grass biomass. Thus, the objective was to evaluate the effect of nitrogen fertilization and plant age effect on the quality of elephant grass biomass for energy purposes. The experiment was performed with genotype Paraíso, grown in a dystrophic Oxisol in the southern state of Tocantins. The design was randomized blocks with subdivided plots, situating plots as nitrogen rates $\left(0,50,100\right.$ and $\left.150 \mathrm{~kg} \mathrm{ha}^{-1}\right)$ and the subplots cutting age $(120,150$ and 180 days after planting ) four replicates. We evaluated the relationship carbon/nitrogen (C:N) and
\end{abstract}

\footnotetext{
${ }^{1}$ Eng $^{\circ}$ Agro , Prof. Dr. Substituto da Universidade Federal de Goiás, UFG, Goiânia. GO. E-mail: rilner1@hotmail.com

${ }^{2}$ Engenheiros Agrônomos Drs. Pesquisadores da Embrapa Agrobiologia. E-mail: urquiaga@cnpab.embrapa.br; bruno@cnpab. embrapa.br

${ }^{3}$ Eng $^{\circ}$ Agr ${ }^{\circ}$, Prof. Dr. Adjunto da Universidade Federal de Goiás, UFG. E-mail: leouft@gmail.com

${ }^{4}$ Eng ${ }^{\circ}$ Agrícola M.Sc., Prof. da Escola Fazenda Emílio Schroeder. E-mail: zanettijb@yahoo.com.br

${ }^{5}$ Eng $^{\circ}$ Agro, Prof. Dr. Adjunto da UNESP. Faculdade de Ciências Agrárias e Veterinárias, Campus de Jaboticabal, SP. E-mail: rmprado@fcav.unesp.br

* Autor para correspondência
} 
leaf/stem (L:S), levels of neutral detergent fiber (NDF) and ash contents in dry biomass produced. The application of nitrogen increased by $12 \%$ to $\mathrm{C}: \mathrm{N}$ ratio of the plant. The advanced age of cut forage was increased $9 \%$ in the C:N plant, however, decreased by 12 and $14 \%$ levels of ash produced in the stem and leaves, respectively. The production of elephant grass for agrifuels is feasible with management system proposed, quality characteristics desirable, such as high C:N ratio, above $40 \%$ and higt fiber content, above $50 \%$.

Key words: Pennisetum purpureum, nitrogen fertilization, bioenergy

\section{Introdução}

Um dos grandes desafios para a pesquisa atualmente é a produção de material energético alternativo por meio de biomassa vegetal, já que a continuação da queima desenfreada de petróleo, além de ser finita, contribui para o efeito estufa que ameaça o equilíbrio do clima da terra (MORAIS et al., 2009). Desse modo, o problema da demanda energética vem se tornando uma preocupação mundial. Assim, muitos países vêm buscando alternativas ao uso de combustíveis fósseis, reduzindo a dependência principalmente do petróleo e seus derivados (MONTI et al., 2007).

$\mathrm{O} \mathrm{CO}_{2}$ atmosférico é fonte de $\mathrm{C}$ para o crescimento das plantas, por meio do processo fotossintético. Pode-se considerar que esta fonte é ilimitada, e, por isso, a acumulação de biomassa pelas plantas dependerá de outros fatores que afetam o crescimento vegetal, tais como: disponibilidade de nutrientes, condições físicas e químicas do solo, disponibilidade de água e adequada temperatura (URQUIAGA; ALVES; BODDEY, 2006). Como a queima da biomassa somente recicla $\mathrm{CO}_{2}$ que foi retirado da atmosfera tudo indica que, em longo prazo, o uso da biomassa vegetal será uma das alternativas energéticas mais seguras (SCHEMER et al., 2008).

O Cerrado brasileiro é uma região que tem grande potencial de produção de alimentos e energia para suprir as necessidades do país e de outras partes do mundo (RESCK et al., 2008). O clima é estacional, com período chuvoso e seco, bem definidos. A precipitação média anual é de 1.500 $\mathrm{mm}$ e as temperaturas são geralmente amenas ao longo do ano, entre 22 e $27{ }^{\circ} \mathrm{C}$ em média. Os solos no Cerrado caracterizam-se, em sua grande maioria, por serem altamente intemperizados, com baixa fertilidade (RESCK et al., 2008). Neste contexto, uma análise de fontes alternativas de energia e da qualidade do material produzido, como o poder calorífico, por exemplo, torna-se necessário para melhor conhecimento do potencial de produção da bioenergia na região de Cerrado.

Pesquisas recentes vêm desenvolvendo novas técnicas de uso de biomassa de capim-elefante como fonte de energia alternativa, e neste sentido, novo rumo deve ser dado em relação às características que se deseja obter da planta (URQUIAGA; ALVES; BODDEY, 2006). O capim-elefante tem uma grande semelhança ao bagaço de cana-deaçúcar, que tem em sua composição $65 \%$ de fibras e $35 \%$ de material não fibroso, sendo o teor de fibras fundamental para a produção de carvão (MORAIS, 2008). Relatos de pesquisa mostram que a produção anual desse material pode superar $100 \mathrm{Mg} \mathrm{ha}^{-1}$, desde que genótipos eficientes sejam usados e condições edafoclimáticas favoráveis sejam garantidas (URQUIAGA; ALVES; BODDEY, 2006).

Com o melhoramento genético do capimelefante, tem-se observado que em geral a forrageira apresenta melhorias a resposta a aplicação de adubos nitrogenados (MISTURA et al., 2006), especialmente quando sua biomassa está direcionada para a nutrição animal. Por outro lado, o manejo da idade de corte em gramíneas forrageiras, afeta o rendimento da forragem colhida, podendo resultar em efeitos significativos na produção e qualidade da biomassa seca (MAGALHÃES et al., 2006). Para a produção de energia alternativa a partir de biomassa de capim-elefante, os teores de alguns sais produzidos, como o potássio tem grande 
importância, pois a presença de altas concentrações pode provocar perda de qualidade do capim.

O manejo adequado dos fertilizantes, principalmente os nitrogenados, considerando a pobreza na disponibilidade deste nutriente no solo, será fundamental para obter ganhos de produtividade, principalmente racionalizando o uso deste insumo agrícola devido aos altos níveis de energia fóssil que demanda sua síntese; e melhoria na qualidade da biomassa produzida, sendo mais rica em fibras e lignina. Aliado a isso, como mencionado anteriormente, os adubos nitrogenados são os que mais demandam energia fóssil, repercutindo no consumo de energia na produção agropecuária, chegando a responder por até $50 \%$ de toda energia consumida nas etapas agrícolas de um sistema de produção (CLEVELAND, 1995; LÆGREID; BØCKMAN; KAARSTAD, 1999; PIMENTEL; PATZEK, 2005), o que aumenta ainda mais a importância de reduzir ou otimizar o uso desse nutriente no sistema de produção, visando sempre ter um alto ganho de energia renovável.

Diante desse contexto, objetivou-se avaliar o efeito da adubação nitrogenada e idade de corte do capim-elefante na qualidade da biomassa produzida para fins agroenergéticos, na região do Cerrado.

\section{Material e Métodos}

O experimento foi realizado na área experimental da Universidade Federal do Tocantins, em Gurupi TO, em um Latossolo Vermelho Amarelo distrófico. O plantio foi realizado em 1 de dezembro de 2008. Realizou-se a amostragem do solo, na profundidade de 0-20 cm, e posterior análise química, seguindo o método proposto pela Embrapa (1997), apresentando os seguintes resultados: matéria orgânica $17,9 \mathrm{~g} \mathrm{~kg}^{-1}$; nitrogênio $1,1 \mathrm{~g} \mathrm{~kg}^{-1}$; carbono $11,0 \mathrm{~g} \mathrm{~kg}^{-1} ; \mathrm{pH}\left(\mathrm{H}_{2} \mathrm{O}\right)$ 5,8; alumínio $0,1 \mathrm{mmol}_{\mathrm{c}} \mathrm{dm}^{-3}$; cálcio + magnésio $32,0 \mathrm{mmol}_{\mathrm{c}} \mathrm{dm}^{-3}$; potássio 1,6 $\mathrm{mmol}_{\mathrm{c}} \mathrm{dm}^{-3}$; fósforo (Mehlich) 14,0 $\mathrm{mg} \mathrm{dm}^{-3}$.

Pode-se salientar que antes da implantação deste trabalho, a área foi cultivada em sistema de plantio direto, sendo realizado uso de plantas leguminosas como crotalária, feijão guandu, feijão de porco, consorciadas com algodão e milho antes da introdução da cultura principal.

Para a instalação do experimento, foi realizado o preparo de solo por meio do sistema convencional, com aração e gradagem, e em seguida foi feita a abertura dos sulcos para a adubação de correção e posteriormente realizou-se a semeadura do capimelefante. Utilizou-se o genótipo Paraíso, sendo este híbrido de capim-elefante (Pennisetum hybridum), provindo do cruzamento do capim-elefante comum (Pennisetum purpureum Schum.) com o milheto (Pennisetum americanum), tendo alta rusticidade e produção de biomassa.

Os tratamentos foram doses de nitrogênio $(0$, $50,100,150 \mathrm{~kg} \mathrm{ha}^{-1} \mathrm{ano}^{-1}$ ), na forma de uréia, e três idades de corte (120, 150 e 180 dias após o plantio), com quatro repetições. Desta forma, o delineamento estatístico corresponde a parcelas subdivididas, onde as parcelas receberam os tratamentos que correspondem às quatro doses de nitrogênio, e as subparcelas os tratamentos que correspondem às três idades de corte. Na adubação de plantio foram aplicados $100 \mathrm{~kg} \mathrm{ha}^{-1}$ de $\mathrm{K}_{2} \mathrm{O}$ e de $\mathrm{P}_{2} \mathrm{O}_{5}$, na forma de cloreto de potássio e superfosfato simples, respectivamente. A adubação foi realizada no sulco de plantio, com $30 \mathrm{~cm}$ de profundidade.

A unidade experimental foi constituída de quatro linhas de capim-elefante com cinco metros de comprimento, espaçadas de um metro, totalizando $20 \mathrm{~m}^{2}$ por parcela. Durante o período experimental, foram efetuadas duas capinas mecânica, aos 30 e 60 dias após o plantio do capim-elefante. Os dados meteorológicos foram coletados na área, durante o período experimental, com temperatura mínima de 20,5 a $22,4{ }^{\circ} \mathrm{C}$ e máxima de 30,4 a 31,9 ${ }^{\circ} \mathrm{C}$ nos meses de novembro até maio de 2009 , e a precipitação variando de 154,8 a $283,4 \mathrm{~mm}$ mensais entre os meses de novembro a abril, sendo menor apenas no mês de maio com 70,2 mm. Pode-se 
observar que durante o ciclo do capim não houve restrição térmica ou hídrica importante que poderia limitar o desenvolvimento da cultura, aproveitando assim a maior parte do período chuvoso da região de Gurupi-TO.

Para a determinação da relação colmo:folha (C:F) da forrageira, foram realizadas amostragens a partir de cinco plantas coletadas aleatoriamente dentro de cada parcela aos 120, 150 e 180 dias após o plantio da forrageira. A biomassa das amostras de colmo e folhas foram pesadas, e logo após foram retiradas subamostras para secagem em estufa a $65{ }^{\circ} \mathrm{C}$, até peso constante, para determinação da fração da matéria seca de colmo e de folhas. A relação colmo:folha da forrageira foi obtida através da divisão do total de biomassa seca de colmos produzidos pelo total da biomassa seca de folhas.

Em seguida, as amostras de plantas foram pré-moídas em moinho tipo Willey (peneiras de $2 \mathrm{~mm}$ ), para determinação do teor de N-total no tecido vegetal, seguindo a metodologia descrita por Alves et al. (1994). Foi determinado o acúmulo de nitrogênio tanto nas folhas como nos colmos do capim-elefante. A relação $\mathrm{C}: \mathrm{N}$ da forrageira foi obtida pela divisão do teor de carbono acumulado na matéria seca (sendo estabelecido um teor de $45 \%$ de carbono da biomassa seca) pelo teor de nitrogênio total contido na matéria seca na parte aérea de capim-elefante. A determinação do teor de fibra do capim-elefante seguiu a metodologia proposta por Van Soest e Wine (1965) e descrito por Silva (1990), sendo baseada na separação das frações constituintes das forrageiras, por meio de reagentes específicos denominados detergentes. Para a determinação das cinzas, foi retirado uma subamostra e levada ao forno com temperatura a $600{ }^{\circ} \mathrm{C}$ durante três horas. A percentagem de cinzas foi obtida pela diferença do peso inicial para o peso final do cadinho após a combustão da amostra.

Os dados obtidos após a condução do experimento foram submetidos às análises de variância, ajustados às regressões polinomiais, sendo os dados em função das doses de nitrogênio e idade de corte do capimelefante submetida a analise estatística de variância com aplicação do teste $\mathrm{F}$, em esquema fatorial 4x3 (quatro doses e três idades de corte). As análises foram realizadas com auxílio do pacote estatístico AgroEstat (BARBOSA; MALDONADO, 2011), ao nível de $5 \%$ de probabilidade.

\section{Resultados e Discussão}

As doses de nitrogênio e idade de corte do capim-elefante, influenciaram significativamente a relação $\mathrm{C}: \mathrm{N}$ da parte aérea da forrageira, entretanto não afetou a relação $\mathrm{C}: \mathrm{F}$ (Tabela 1 ). Do mesmo modo, a ausência de efeito do nitrogênio na relação C:F do capim-elefante, também foi relatado por Andrade et al. (2003). Em relação à idade do corte, não houve uma influência na relação $C: F$ da forrageira, discordando de autores como Santana, Pereira e Arruda (1989); Queiroz Filho, Silva e Nascimento (2000); Leite, Queiroz Filho e Silva (2000) e Bhering et al. (2008). A ausência do efeito de um possível aumento da relação C:F com a idade da planta, pelo aumento da quantidade de compostos lignificados e fibrosos, estaria associada às condições edafoclimáticas da região durante o período de desenvolvimento do estudo, pois houve precipitações pluviais até o último mês de avaliação, e pode ter estimulado a emissão de novas folhas evitando aumento significativo na relação $C: F$ do capim-elefante. 
Tabela 1. Relação carbono:nitrogênio (C:N) e Relação colmo:folha (C:F) do capim-elefante cv. Paraíso, em função de quatro doses de nitrogênio e três idades de corte, cultivados no campus experimental da UFT, município de GurupiTO, 2009.

\begin{tabular}{lcc}
\hline Tratamentos & Relação C:N & Relação C:F \\
\hline Doses de nitrogênio (D) $\left(\mathrm{kg} \mathrm{ha}^{-1} \mathrm{de}\right.$ N) & & \\
0 & 37,3 & 5,1 \\
50 & 35,9 & 5,0 \\
100 & 40,3 & 5,0 \\
150 & 41,7 & 4,9 \\
Teste F & $43,6^{* *}$ & $0,4^{\text {ns }}$ \\
& & \\
Idade de planta (I) (dias após brotamento) & & \\
120 & 36,9 & 5,1 \\
150 & 39,1 & 5,0 \\
180 & 40,4 & 4,9 \\
Teste F & $13,4^{* *}$ & $0,02^{\text {ns }}$ \\
& & \\
(D) x (I) & $1,51^{\text {ns }}$ & Teste F \\
C.V. (\%) & 3,6 & $8,8^{\text {ns }}$ \\
\hline
\end{tabular}

${ }^{\text {ns }} \mathrm{e}^{* *}$ - não significativo a $5 \%$ e significativo a $1 \%$ de probabilidade pelo teste $\mathrm{F}$, respectivamente.

Fonte: Elaboração dos autores.

A relação $\mathrm{C}: \mathrm{N}$ do capim-elefante aumentou tanto em função da aplicação de doses crescentes de nitrogênio como em função do aumento da idade do corte, sendo observado um ajuste ao modelo quadrático e linear da regressão, respectivamente (Figuras 1 A, B). Observou-se que o emprego da dose de nitrogênio igual a $150 \mathrm{~kg} \mathrm{ha}^{-1}$ e associado com a idade de corte do capim aos 180 dias após o brotamento, é importante para ter biomassa com maior relação $\mathrm{C}: \mathrm{N}$, sendo mais fibroso e mesmo assim, os valores encontrados para a relação $\mathrm{C}: \mathrm{N}$ da forrageira foram inferiores aos obtidos por Morais (2008), o qual encontrou uma relação C:N variando entre 80 e 156, enquanto que a maior relação C:N obtida no presente estudo foi de 42 . A baixa relação encontrada é devida ao alto teor de nitrogênio presente no solo durante a condução do estudo aliado às condições climáticas favoráveis para o cultivo do capim-elefante (temperatura média de $26{ }^{\circ} \mathrm{C}$ e precipitação média de $220 \mathrm{~mm}$ durante os meses de condução do experimento), possivelmente aumentando a disponibilidade de $\mathrm{N}$ no sistema, favorecendo a baixa relação C:N no tecido vegetal do capim-elefante. lignificado, ou seja, com melhores condições para o uso energético.

A aplicação de $\mathrm{N}$-fertilizante não influenciou os teores de FDN no colmo e na folha do capimelefante, apresentando em média 69 e 58\%, respectivamente (Tabela 2). Assim, a ausência de efeito do nitrogênio nos teores de fibras também foram relatados por Moir (1974), Ribeiro, Gomide e Paciullo (1999) e Magalhães et al. (2009). Porém, Ribeiro, Gomide e Paciullo (1999), Mistura (2001) e Mistura et al. (2007) apontaram incremento nos teores de FDN em folhas de capim-elefante em função das doses de nitrogênio aplicadas. De acordo com Mistura et al. (2007) esses altos valores ocorrem devido aos fatores edafoclimáticos favoráveis durante o período de avaliação do estudo e à maior disponibilidade de nutrientes minerais na solução do solo, proporcionando maior crescimento e desenvolvimento de perfilhos de capim-elefante. 
Figura 1. Relação C:N (média das três idades de corte) em função das doses de nitrogênio aplicado (A), e em função da idade de corte (B, média das quatro doses de N) do capim-elefante cv. Paraíso, cultivado em Gurupi-TO, 2009. ** - significativo ao nível de $1 \%$ de probabilidade.
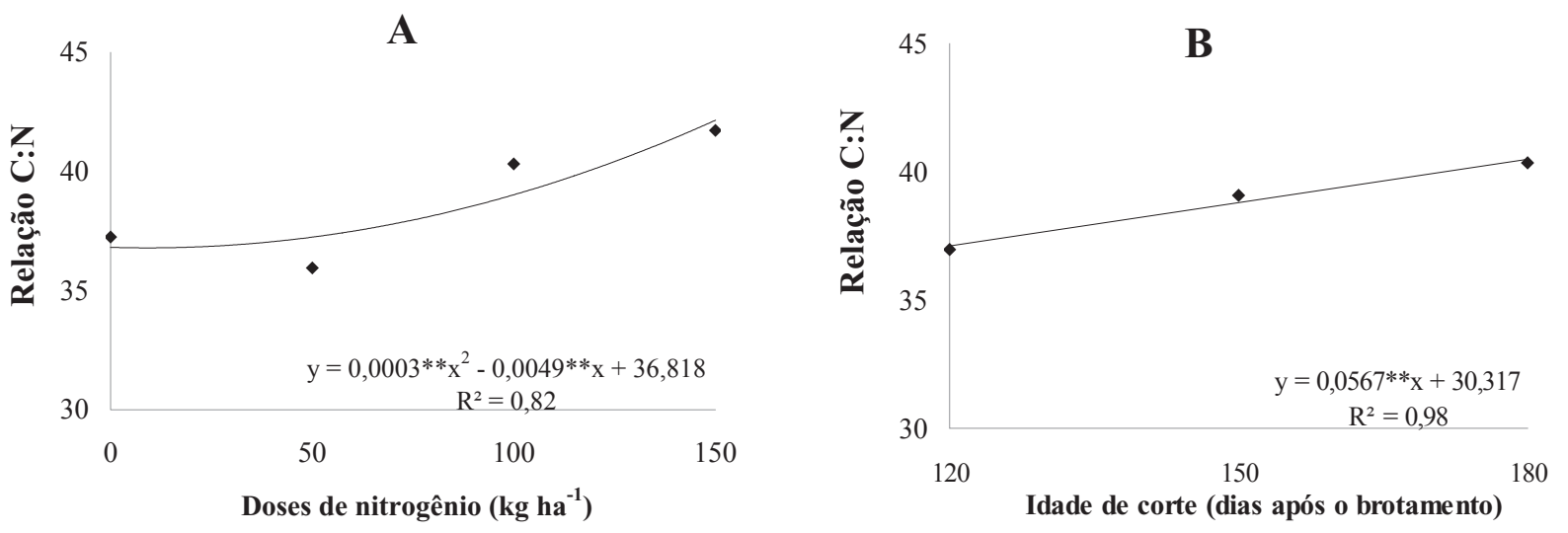

Fonte: Elaboração dos autores.

Tabela 2. Fibras em detergente neutro (FDN) no colmo e na folha do capim-elefante cv. Paraíso, em função de quatro doses de nitrogênio e três idades de corte, cultivados no campus experimental da UFT, município de Gurupi-TO, 2009.

\begin{tabular}{|c|c|c|}
\hline \multicolumn{3}{|c|}{ Fibras em Detergente Neutro - FDN } \\
\hline Tratamentos & Colmo & Folha \\
\hline \multicolumn{3}{|c|}{-----------------\% ----------------- } \\
\hline \multicolumn{3}{|c|}{ Doses de N (D) $\left(\mathrm{kg} \mathrm{ha}^{-1}\right.$ de N) } \\
\hline 0 & 68,7 & 58,3 \\
\hline 50 & 69,1 & 57,4 \\
\hline 100 & 69,6 & 58,4 \\
\hline 150 & 68,4 & 56,5 \\
\hline Teste F & $0,2^{\mathrm{ns}}$ & $1,2^{\mathrm{ns}}$ \\
\hline \multicolumn{3}{|c|}{ Idade de planta (I) (dias após brotamento) } \\
\hline 120 & 69,0 & 58,1 \\
\hline 150 & 71,7 & 58,0 \\
\hline 180 & 66,3 & 56,9 \\
\hline Teste F & $16,2 * *$ & $1,1^{\text {ns }}$ \\
\hline \multicolumn{3}{|c|}{ Teste $\mathbf{F}$} \\
\hline (D) $\mathrm{x}(\mathrm{I})$ & $0,5^{\text {ns }}$ & $0,2^{\mathrm{ns}}$ \\
\hline C.V. $(\%)$ & 5,2 & 4,8 \\
\hline
\end{tabular}

${ }^{\text {ns }} e^{* *}$ - não significativo a $5 \%$ e significativo a $1 \%$ de probabilidade pelo teste $\mathrm{F}$, respectivamente.

Fonte: Elaboração dos autores.

A aplicação de nitrogênio não afetou os teores de cinzas no colmo do capim-elefante, apresentando em média 5,3\% (Tabela 3). O nitrogênio aplicado incrementou, com ajuste quadrático, os teores de cinzas nas folhas, atingindo $10,3 \%$ na dose de 77,5 $\mathrm{kg} \mathrm{ha}^{-1}$ de N (Figura 3A). Observou-se que tanto na folha como no colmo, a idade do corte diminuiu os teores de cinzas no capim-elefante (Tabela 3), com ajuste quadrático (Figura 3B) e linear (Figura 3C), respectivamente. Mesmo assim, esses valores podem ser considerados altos para o uso com finalidade energética, pois estudos realizados por Quesada (2005), os teores de cinzas foram de 8,1 e $1,2 \%$ na folha e no colmo, respectivamente. 
Morais (2008) encontrou menores teores de cinzas na folha, variando entre $1,8-3,8 \%$, e no colmo $4-5 \%$. Em ambos os estudos os experimentos foram desenvolvidos em solos de baixa fertilidade, diferente do solo utilizado para esse trabalho onde havia boa disponibilidade de nutrientes favorecendo na melhor nutrição do capim-elefante, sendo observada pela maior produção em matéria seca, quando comparados aos resultados encontrados por Quesada (2005) e Morais (2008) num mesmo período de avaliação.

Figura 2. Fibras em detergente neutro (FDN) no colmo (média das quatro doses de N) em função da idade de corte do capim-elefante cv. Paraíso, cultivado em Gurupi-TO, 2009. ** * - significativo a 1 e 5\% de probabilidade, respectivamente.

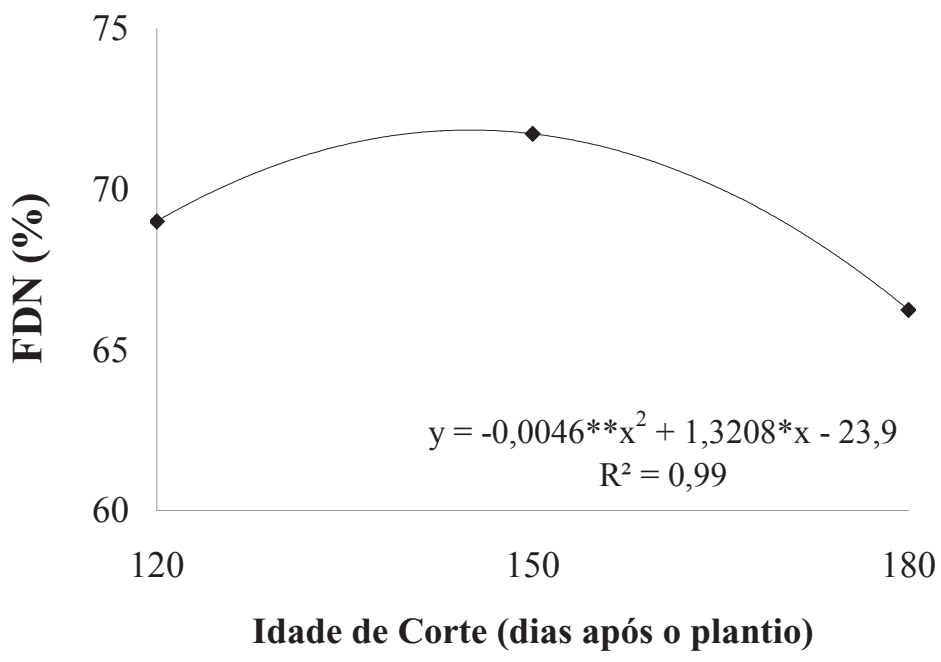

Fonte: Elaboração dos autores.

Tabela 3. Teores de cinzas no colmo e na folha do capim-elefante cv. Paraíso, em função de quatro doses de nitrogênio e três idades de corte, cultivados no campus experimental da UFT, município de Gurupi-TO, 2009.

\begin{tabular}{|c|c|c|}
\hline \multicolumn{3}{|c|}{ Cinzas } \\
\hline Tratamentos & Colmo & Folha \\
\hline & -------- & ----- \\
\hline \multicolumn{3}{|c|}{ Doses de $\mathbf{N}$ (D) $\left(\mathrm{kg} \mathrm{ha}^{-1}\right.$ de N$)$} \\
\hline 0 & 5,2 & 9,7 \\
\hline 50 & 5,4 & 10,2 \\
\hline 100 & 5,7 & 10,1 \\
\hline 150 & 5,1 & 9,5 \\
\hline Teste F & $2,1^{\mathrm{ns}}$ & $4,9^{*}$ \\
\hline \multicolumn{3}{|c|}{ Idade de planta (I) (dias após brotamento) } \\
\hline 120 & 5,7 & 10,4 \\
\hline 150 & 5,4 & 10,3 \\
\hline 180 & 5,0 & 8,9 \\
\hline Teste F & $7,1^{* *}$ & $13,4^{* *}$ \\
\hline \multicolumn{3}{|c|}{ Teste $\mathbf{F}$} \\
\hline (D) $\mathrm{x}$ (I) & $1,1^{\mathrm{ns}}$ & $1,2^{\mathrm{ns}}$ \\
\hline C.V. $(\%)$ & 11,8 & 7,8 \\
\hline
\end{tabular}

ns, $* * *$ - não significativo, significativo a $5 \%$ e a $1 \%$ de probabilidade pelo teste $\mathrm{F}$, respectivamente.

Fonte: Elaboração dos autores. 
Figura 3. Teores de cinzas na folha (média das três idades de corte) em função da dose de nitrogênio aplicado (A); na folha (B) e no colmo (C) (média das quatro doses de N) em função da idade de corte do capim-elefante cv. Paraíso, cultivado em Gurupi-TO, 2009. ns, * ** - nãosignificativo a $5 \%$, significativo a 5 e $1 \%$ de probabilidade, respectivamente.
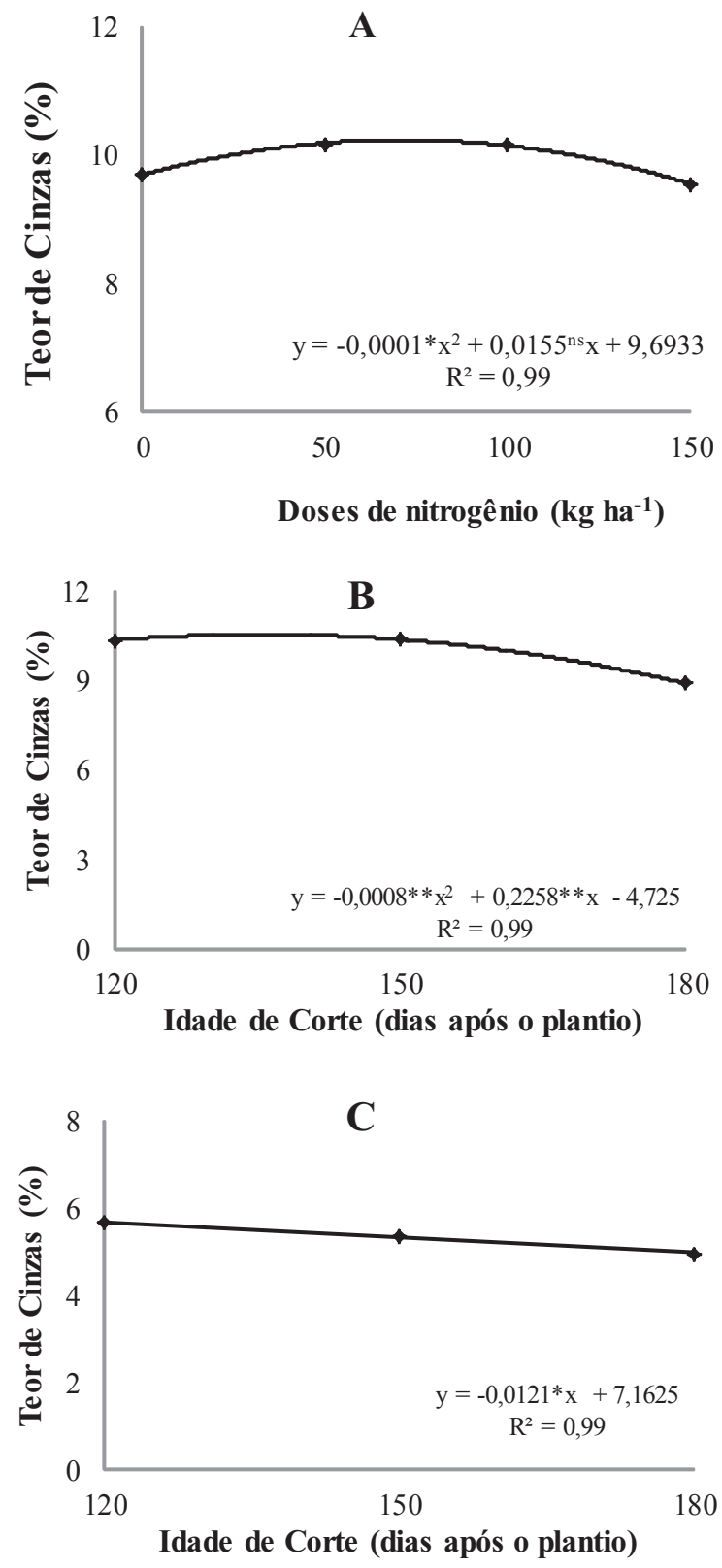

Fonte: Elaboração dos autores.
Vale ressaltar, que os valores de cinzas encontrados por Quesada (2005) e Morais (2008) foram obtidos por meio do fracionamento das fibras em detergente ácido (FDA), proposto por Van Soest e Wine (1968), nessa metodologia não se leva à mufla todo o material e sim, é feita por um fracionamento físico do material para a determinação de fibras em detergente ácido (FDA) realizando uma separação das frações constituintes das forrageiras, por meio de substancias específicas denominadas reagentes, onde ocasiona a solubilização do conteúdo celular, podendo subestimar o percentual de cinzas realmente produzido, uma vez que solubiliza os sais que não são contabilizados para tal determinação final. Contudo, tornam-se necessários estudos que visam o melhor manejo da adubação nitrogenada e idade de corte do capim-elefante, visto que estudos realizados por Seye (2003) avaliando os teores de cinzas produzidas no bagaço e na palha da cana e o capim-elefante foi observado teores médios de 4,$1 ; 7,1$ e $11,5 \%$, respectivamente. O maior teor de cinzas observado no capim-elefante foi atribuído às altas aplicações de adubos nitrogenados, chegando a $400 \mathrm{~kg}$ de $\mathrm{N} \mathrm{ha}^{-1} \mathrm{ano}^{-1}$. Materiais com maiores teores de cinzas na sua composição química têm o máximo desprendimento de voláteis a temperaturas mais elevadas. $\mathrm{O}$ alto teor de cinzas produzidas pode inviabilizar a utilização desse material com finalidade energética para indústrias num processo de gaseificação. Porém, torna-se possível para a queima direta e/ou carvoejamento, pela possibilidade de reutilizar as cinzas produzidas na produção agrícola de biomassa no campo, fechando assim o ciclo eficiente da produção de biomassa com a finalidade energética. 


\section{Conclusões}

A aplicação de nitrogênio incrementou em 12\% a relação $\mathrm{C}: \mathrm{N}$ da planta.

A maior idade de corte da forrageira incrementouse em 9\% a relação C:N da planta, entretanto, diminuiu em 12 e $14 \%$ os teores de cinzas produzidas no colmo e nas folhas, respectivamente.

A produção de capim-elefante para fins agroenergéticos é viável com o sistema de manejo proposto, pois apresentou características qualitativas desejáveis, como alta relação C:N, acima de 40 e altos teores de fibras, acima de 50\%.

\section{Referências}

ALVES, B. J. R.; SANTOS, J. C. F.; URQUIAGA, S.; BODDEY, R. M. Métodos de determinação do nitrogênio em solo e planta. In: HUNGRIA, M.; ARAUJO, R. S. (Ed.). Manual de métodos empregados em estudos de microbiologia agrícola. Brasília: Embrapa-SPI, 1994. p. 409-449. (Embrapa-CNPAF. Documentos, 46).

ANDRADE, A. C.; FONSECA, D. M.; QUEIROZ, D. S.; SALGADO, L. T.; CECON, P. R. Adubação nitrogenada e potássica em capim-elefante (Pennisetum purpureum Schum. cv. Napier). Ciência Agrotécnica, Lavras, v. 27, p. 1643-1651, 2003. Edição Especial.

BARBOSA, J. C.; MALDONADO JÚNIOR, W. AgroEstat versão 1.0. - sistema para análise estatística de ensaios agronômicos. Jaboticabal: Universidade Estadual Paulista, 2011.

BHERING, M.; CABRAL, L. S.; ABREU, J. G.; SOUZA, A. L.; ZERVOUDAKIS, J. T.; RODRIGUES, R. S.; PEREIRA, G. A. C.; REVERDITO, R.; OLIVEIRA, I. S. Características agronômicas do capim-elefante Roxo em diferentes idades de corte na depressão Cuiabana. Revista Brasileira de Saúde e Produção Animal, Salvador, v. 9, n. 3, p. 384-396, 2008.

CLEVELAND, C. J. The direct and indirect use of fossil fuels and electricity in USA agriculture 1910-1990. Agriculture, Ecosystems and Environment, Amsterdam, v. 55, n. 2, p. 111-121, 1995.

EMPRESA BRASILEIRA DE PESQUISA AGROPECUÁRIA - EMBRAPA. Manual de métodos de análise de solos. 2. ed. Rio de Janeiro, 1997. 212 p. (EMBRAPA-CNPS. Documento, 1).
LÆGREID, M.; BØCKMAN, O. C.; KAARSTAD, O. Agriculture, fertilizers and the environment. Wallingford: CABI, 1999. $320 \mathrm{p}$.

LEITE, R. M. B.; QUEIROZ FILHO, J. L.; SILVA, D. S. Produção e valor nutritivo do capim-elefante cultivar Cameroon em diferentes idades. Agropecuária Técnica, Areia, PB, v. 21, n. 1- 2, p. 30-39, 2000.

MAGALHÃES, J. A.; LOPES, E. A.; RODRIGUES, B. H. N.; COSTA, N. L.; BARROS, N. N.; MATTEI, D. A. Influência da adubação nitrogenada e da idade de corte sobre o rendimento forrageiro do capim-elefante. Revista Ciência Agronômica, Fortaleza, CE, v. 37, n. 1, p. 91-96, 2006.

MAGAlHÃES, J. A.; RODRIGUES, B. H. N.; CARNEIRO, M. S. S.; ANDRADE, A. C.; COSTA, N. L.; PINTO, M. S. C.; FILHO, W. J. E. M. Influência da adubação nitrogenada e da idade de corte sobre os teores de proteína bruta e fibra em detergente neutro de três cultivares de capim-elefante, REDVET - Revista Eletrônica de Veterinária, Málaga, v. 10, n. 4, p. 1-12, 2009.

MARTINS-COSTA, R. H. A.; CABRAL, L. S.; BHERING, M.; ABREU, J. G.; ZERVOUDAKIS, J. T.; RODRIGUES, R. C.; OLIVEIRA, I. S. Valor nutritivo do capim-elefante obtido em diferentes idades de corte. Revista Brasileira de Saúde e Produção Animal, Salvador, v. 9, n. 3, p. 397-406, 2008.

MISTURA, C. Doses crescente de nitrogênio e fósforo na produção e qualidade do capim-elefante-anão (Pennisetum purpureum Schum. cv. Mott.). 2001. Dissertação (Mestrado em Agronomia) - Universidade Federal de Pelotas, Pelotas.

MISTURA, C.; FAGUNDES, J. F.; FONSECA, D. M.; MOREIRA, L. M.; VITOR, C. M. T.; NASCIMENTO JÚNIOR, D.; RIBEIRO JÚNIOR, J. I. Disponibilidade e qualidade do capim-elefante com e sem irrigação adubado com nitrogênio e potássio na estação seca, Revista Brasileira de Zootecnia, Viçosa, v. 35, n. 2, p. 372-379, 2006.

MISTURA, C.; FONSECA, D. M.; MOREIRA, L.M.; FAGUNDES, J. F.; MORAIS, R. V.; QUEIROZ, A. C.; RIBEIRO JÚNIOR, J. I. Efeito da adubação nitrogenada e irrigação sobre a composição químico-bromatológica das lâminas foliares e da planta inteira de capim-elefante sob pastejo, Revista Brasileira de Zootecnia, Viçosa, v. 36, n. 6, p. 1707-1714, 2007.

MOIR, K. W. The constancy of the digested cell wall in grasses. Journal of Agricultural Science, Cambridge, v. 83, n. 2, p. 259-258, 1974. 
MONTI, A.; FAZIO, S.; LYCHNARAS, V.; SOLDATOS, P.; VENTURI, G. A full economic analysis of switchgrass under different scenarios in Italy estimated by BEE model. Biomass and Bioenergy, Rotterdam, v. 31, n. 4, p. 177-185, 2007.

MORAIS, R. F. Potencial produtivo e eficiência da fixação biológica de nitrogênio de cinco genótipos de capim-elefante (Pennisetum purpureum Schum.), para uso como fonte alternativa de energia. 2008. Dissertação (Mestrado em Agronomia) - Universidade Federal Rural do Rio de Janeiro, Seropédica.

MORAIS, R. F.; SOUZA, B. J.; LEITE, J. M.; SOARES, L. H.; ALVES, B. J.; BODDEY, R. M.; URQUIAGA, S. U. Produção, qualidade de biomassa e fixação biológica de $\mathrm{N}$ em genótipos de capim-elefante destinados à geração de energia. Pesquisa Agropecuária Brasileira, Brasília, v. 44, n. 2, p. 133-140, 2009.

PIMENTEL, D.; PATZEK, T. Ethanol production using corn, switchgrass, and wood; biodiesel production using soybean and sunflower. Natural Resources Research, New York, v. 14, n. 1, p. 65-76, 2005.

QUEIROZ FILHO, J. L.; SILVA, D. V.; NASCIMENTO, I. S. Produção de matéria seca e qualidade do capimelefante (Pennisetum purpureum Schum.) cultivar Roxo em diferentes idades de corte. Revista Brasileira de Zootecnia, Viçosa, MG, v. 29, n. 1, p. 69-74, 2000.

QUESADA, D. M. Parâmetros quantitativos $e$ qualitativos da biomassa de diferentes genótipos capimelefante para produção de agroenergéticos. 2005. Tese (Doutorado em Agronomia) - Universidade Federal Rural do Rio de Janeiro, Seropédica.

RESCK, D. V. S.; FERREIRA, E. A. B.; FIGUEIREDO, C. C.; ZINN, Y. L. Dinâmica da matéria orgânica no Cerrado. In: SANTOS, G. A.; SILVA, L. S.; CANELLAS, L. P.; CAMARGO, F. A. O. (Ed.). Fundamentos da matéria orgânica do solo - ecossistemas tropicais e subtropicais. Porto Alegre: Genesis, 2008. p. 359-406.
RIBEIRO, K. G.; GOMIDE, J. A.; PACIULLO, D. S. C. Adubação nitrogenada do capim-elefante cv. Mott. 2. Valor nutritivo ao atingir 80 e $120 \mathrm{~cm}$ de altura. Revista Brasileira de Zootecnia, Viçosa, MG, v. 28, n. 6, p. 11941202, 1999.

SANTANA, J. P.; PEREIRA, J. M.; ARRUDA, N. G. Avaliação de cultivares de capim-elefante (Pennisetum purpureum Schum.) no Sul da Bahia. I. Agrossistema Cacaueiro. Revista Brasileira de Zootecnia, Viçosa, MG, v. 18, n. 3, p. 273-282, 1989.

SCHEMER, M. R.; VOGEL, K. P.; MITCHELL, R. B.; PERRIN, R. K. Net energy of cellulosic ethanol from switch grass. PNAS, Washington, v. 105, n. 2, p. 464-469, 2008.

SEYE, O. Análise de ciclo de vida aplicada ao processo produtivo de cerâmica estrutural tendo como insumo energético capim-elefante. 2003. Tese (Doutorado em Agronomia) - Universidade Estadual de Campinas, Campinas.

SILVA, D. J. Análise de alimentos; métodos químicos e biológicos. 2. ed. Viçosa: UFV, 1990. 165 p.

URQUIAGA, S.; ALVES, B. J. R.; BODDEY, R. M. Capim-elefante: uma fonte alternativa promissora para a produção de energia. 2006. Disponível em: <www. infobibos.com/Artigos/2006_2/Capimelefante>. Acesso em: 28 nov. 2008.

VAN SOEST, P. J.; WINE, R. H. Determination of lignin and celulose in acid detergent fiber with permanganate. Journal of the Association of Official Analytical Chemists, Washington, v. 51, n. 4, p. 780-785, 1968. 